Click www.researchjournal.co.in/online/subdetail.html to purchase.

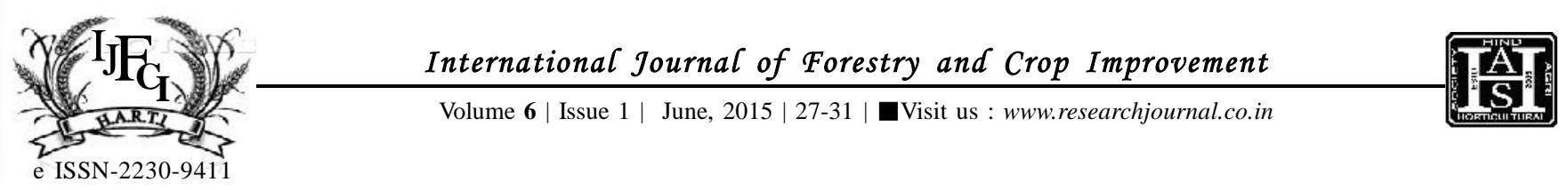

RESEARCH ARTICLE

DOI: $10.15740 / \mathrm{HAS} / \mathrm{IJFCI} / 6.1 / 27-31$

\title{
Impact of source limitation on physiological and biochemical behaviour of rainfed rice genotypes
}

\author{
SHABNAM KHAN, ARTI GUHEY AND V.B. KURUWANSHI
}

\begin{abstract}
Rice is Life" aptly describes the importance of rice in food and nutritional security, particularly for the Asian countries including India. For achieving and maintaining self sufficiency in rice, in view of ever increasing population, rice production has to be enhanced on a continual basis. The appropriate relationship between source sink and their capacity is essential to determine the yield especially in rice. In present investigation the impact of source limitation on assimilate partitioning and yield attributes to optimize the production potential and physiological basis of higher yield contributing traits in the ten genotypes. It was observed that the impact of source limitation was more pronounced in var. Dagad Desi, ARB-6, Ananda which exhibited maximum stability for grain yield. It was mainly due to the proline association with the morphological and phenological parameters as well as physiological behaviour, which ultimately raised growth rate, whereas in (control) Mahamaya and Swarna performed well. Yield was inversely related with ATR. Among cultivars, yield was directly correlated with maximum ATR under stress conditions and cultivar Swarna/ IR and Swarna maintained better translocation under stress than did the other cultivars. It clearly indicates that the defoliation of (100\% leaf removal) plays significant positive contribution in balancing source sink, relatively which influenced the yield of crop and facilitating the better harvesting. Thus, it can be clearly suggested that the leaves (source) could determine the degree of plant performance and control the level of filled grain in rice.
\end{abstract}

KEY WORDS : Source-sink, Defoliation, Assimilate partitioning, Source limitation

How TO CITE THIS ARTICLE : Khan, Shabnam, Guhey, Arti and Kuruwanshi, V.B. (2015). Impact of source limitation on physiological and biochemical behaviour of rainfed rice genotypes. Internat. J. Forestry \& Crop Improv., 6 (1) : 27-31.

Article Chronical : Received : 13.11.2014; Revised : 10.04.2015; Accepted : 13.05.2015 